09,14

\title{
Монодисперсные частицы со структурой ядро-оболочка из магнетита и функционализированного люминофором мезопористого кремнезема
}

(ㄷ Д.А. Еуров ${ }^{1,2}$, Д.А. Курдюков ${ }^{1}$, А.В. Медведев ${ }^{1}$, Д.А. Кириленко ${ }^{1}$, D.R. Yakovlev ${ }^{3}$, В.Г. Голубев ${ }^{1}$

${ }^{1}$ Физико-технический институт им. А.Ф. Иоффе РАН, Санкт-Петербург, Россия

${ }^{2}$ Санкт-Петербургский национальный исследовательский университет информационных технологий, механики и оптики, Санкт-Петербург, Россия

${ }^{3}$ Experimentelle Physik 2, Technische Universität Dortmund, Dortmund, Germany

E-mail: eurov@gvg.ioffe.ru

Поступило в Редакцию 14 апреля 2017 г.

Получены гибридные частицы со структурой ядро-оболочка, представляющие собой монодисперсные сферические мезопористые частицы кремнезема, заполненные магнетитом и покрытые оболочкой мезопористого кремнезема, функционализированной люминесцентным красителем. Частицы имеют низкое среднеквадратичное отклонение размеров (не более 10\%), обладают удельной поверхностью и объемом пор до $250 \mathrm{~m}^{2} / \mathrm{g}$ и $0.15 \mathrm{~cm}^{3} / \mathrm{g}$ соответственно и люминесценцией в видимой области спектра с максимумом на длине волны $530 \mathrm{~nm}$. Частицы могут применяться в тераностике онкологических заболеваний, выполняя одновременно терапевтические (магнитная гипертермия и адресная доставка лекарств) и диагностические (контрастное средство для магнитно-резонансной томографии и люминесцентный маркер) функции.

DOI: 10.21883/PJTF.2017.15.44872.16823

В настоящее время магнитные наночастицы вызывают все больший интерес у исследователей благодаря возможности их применения в биомедицине, например в магнитной гипертермии, магнитно-резонансной томографии (МРТ), адресной доставке лекарств [1-3]. Как правило, для 
этого используют наночастицы оксида железа, в частности магнетита $\left(\mathrm{Fe}_{3} \mathrm{O}_{4}\right)$, которые могут метаболизироваться организмом, обладают низкой токсичностью и уникальными магнитными свойствами, варьируемыми от суперпарамагнитных до ферримагнитных [4-6]. Особое внимание в последние годы уделяют маленьким частицам (размером в единицы-десятки нанометров), которые являются однодоменными. Однодоменные магнитные частицы обладают бо́льшим коэффициентом поглощения при физиологически значимых частотах магнитных полей по сравнению с многодоменными частицами, что важно при их использовании в гипертермии [7]. Однако коллоидные наночастицы магнетита являются агрегативно неустойчивыми в водных средах, что ограничивает возможность их применения в биологии и медицине [8]. Для повышения агрегативной стабильности частицы покрывают кремнеземными или полимерными оболочками, а также обрабатывают поверхностноактивными веществами [7,8]. Кроме того, наночастицы $\mathrm{Fe}_{3} \mathrm{O}_{4}$, традиционно получаемые методом соосаждения $[9,10]$, имеют произвольную форму и значительный разброс по размерам, что затрудняет контроль их фармакодинамических характеристик.

Задачей данной работы являлось получение монодисперсных сферических гибридных частиц со структурой ядро-оболочка на основе мезопористого кремнезема и магнетита, перспективных для использования в тераностике онкологических заболеваний. Для решения поставленной задачи синтезированы нанокластеры магнетита внутри монодисперсных сферических мезопористых частиц кремнезема (МСМЧК), состоящих из плотноупакованных трубок аморфного $\mathrm{SiO}_{2}$ одинакового размера. Полученные МСМЧК, заполненные магнетитом $\left(m \mathrm{SiO}_{2} / \mathrm{Fe}_{3} \mathrm{O}_{4}\right)$, покрывались оболочкой мезопористого кремнезема. На рис. $1, a$ схематично представлен процесс получения частиц со структурой ядро-оболочка $\left(m \mathrm{SiO}_{2} / \mathrm{Fe}_{3} \mathrm{O}_{4} @ m \mathrm{SiO}_{2}\right)$. Для придания частицам люминесцентных свойств проведена функционализация внутренней поверхности пористой оболочки флуоресцеин изотиоцианатом (FITC).

МСМЧК синтезированы гидролизом тетраэтоксисилана в спиртоводно-аммиачной среде, содержащей поверхностно-активный структурообразующий агент [11]. Методика синтеза обеспечивает получение монодисперсных сферических частиц с контролируемо варьируемым средним диаметром в диапазоне от 50 до $1500 \mathrm{~nm}$. Внутри частиц имеется система плотноупакованных монодисперсных цилиндрических пор диаметром $3.1 \pm 0.2 \mathrm{~nm}$. Объемная доля пор составляет $50 \mathrm{vol} \%$ от объема частиц. 


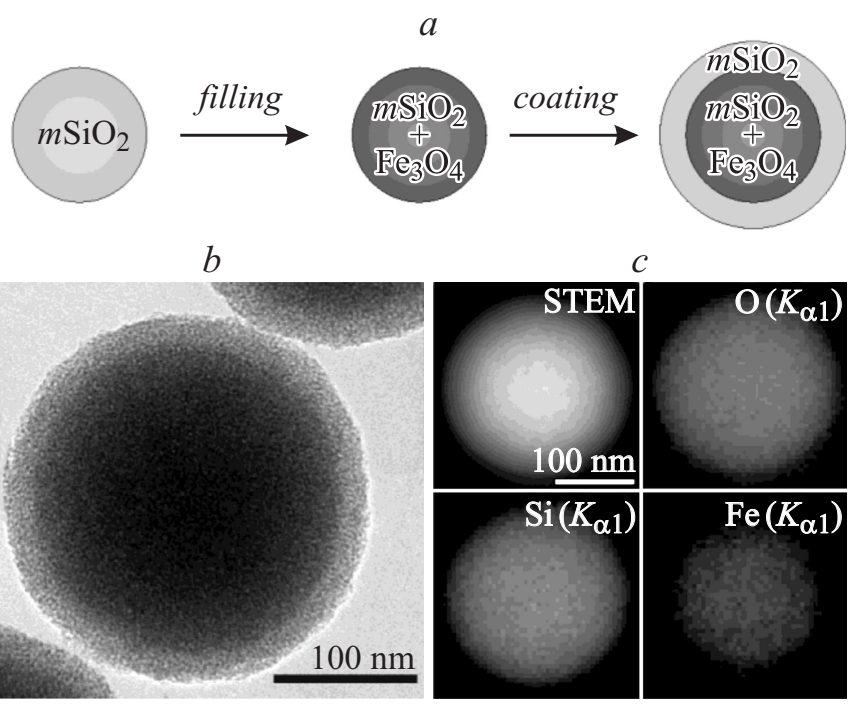

Рис. 1. Схема получения гибридных частиц $m \mathrm{SiO}_{2} / \mathrm{Fe}_{3} \mathrm{O}_{4} @ m \mathrm{SiO}_{2}(a)$, ПЭМизображение частиц $(b)$ и карты распределения элементов, полученные методом PCMA $(c)$ : карты O $\left(K_{\alpha 1}\right), \mathrm{Si}\left(K_{\alpha 1}\right), \mathrm{Fe}\left(K_{\alpha 1}\right)$, полученные от одной частицы, изображенной на левой верхней панели (STEM).

Получение магнетита в порах МСМЧК проводилось в два этапа. На первом этапе в мезопорах частиц синтезированы нанокластеры гематита $\left(\alpha-\mathrm{Fe}_{2} \mathrm{O}_{3}\right)$. Для этого осуществлялась пропитка МСМЧК расплавом кристаллогидрата нитрата железа (III) и проводился отжиг с целью разложения нитрата до $\alpha-\mathrm{Fe}_{2} \mathrm{O}_{3}$. Для достижения большей степени заполнения частиц при однократной пропитке был выбран именно расплав кристаллогидрата, поскольку в расплаве содержится значительно больше целевого вещества в сравнении с раствором $[12,13]$. Степень заполнения пор МСМЧК гематитом составила 30 vol.\% от объема пор. Используемый подход позволяет добиться равномерного распределения нанокластеров $\alpha-\mathrm{Fe}_{2} \mathrm{O}_{3}$ внутри пор МСМЧК и избежать образования массивного $\alpha-\mathrm{Fe}_{2} \mathrm{O}_{3}$ на внешней поверхности частиц [13]. На втором этапе МСМЧК, заполненные $\alpha-\mathrm{Fe}_{2} \mathrm{O}_{3}$, отжигались в потоке водорода при $350^{\circ} \mathrm{C}$ до полного перехода $\alpha-\mathrm{Fe}_{2} \mathrm{O}_{3}$ в $\mathrm{Fe}_{3} \mathrm{O}_{4}$. Магнитные измерения частиц $m \mathrm{SiO}_{2} / \mathrm{Fe}_{3} \mathrm{O}_{4}$ выявляют поведение магнитного

5* Письма в ЖТФ, 2017, том 43, вып. 15 


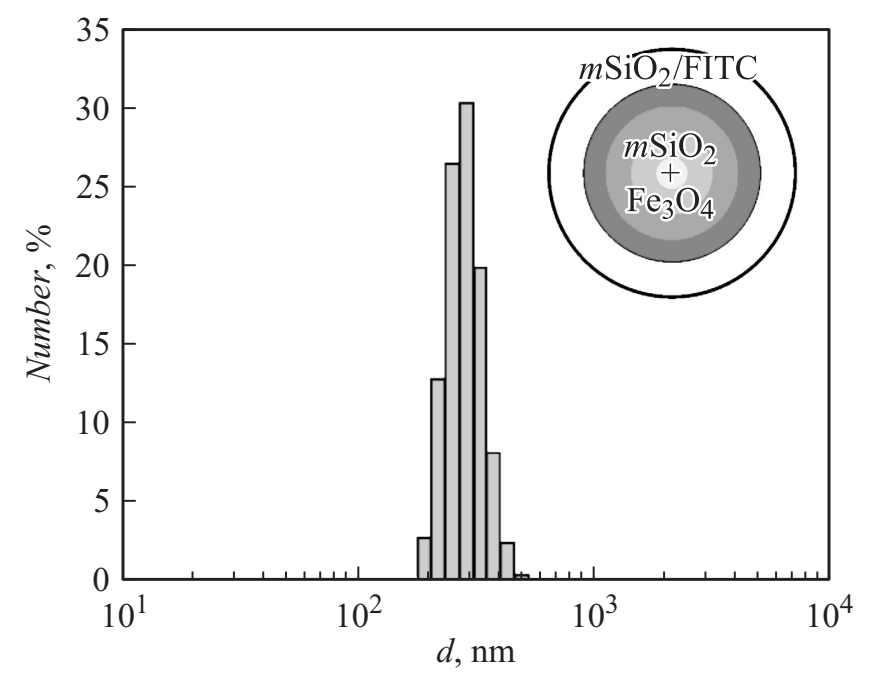

Рис. 2. Распределение гидродинамических диаметров гибридных частиц $m \mathrm{SiO}_{2} / \mathrm{Fe}_{3} \mathrm{O}_{4} @ m \mathrm{SiO}_{2} / \mathrm{FITC}$, измеренное методом динамического светорассеяния. На вставке приведена схема, поясняющая строение частиц.

момента образцов в процессе перемагничивания, обусловленное однодоменными состояниями нанокластеров ферримагнетика $\mathrm{Fe}_{3} \mathrm{O}_{4}$ [13].

Благодаря тому что магнетит находится внутри мезопор МСМЧК, поверхностные свойства полученных частиц $m \mathrm{SiO}_{2} / \mathrm{Fe}_{3} \mathrm{O}_{4}$ практически не отличаются от поверхностных свойств исходных МСМЧК. В результате частицы $m \mathrm{SiO}_{2} / \mathrm{Fe}_{3} \mathrm{O}_{4}$ легко растворяются в воде и образуют агрегативно стабильную суспензию. Такие частицы перспективны для применения в медицине, в частности в магнитной гипертермии, а также в качестве $\mathrm{T}_{2}$-контрастного средства для МРТ [14].

Для придания новых функциональных возможностей полученные частицы $m \mathrm{SiO}_{2} / \mathrm{Fe}_{3} \mathrm{O}_{4}$ покрывались оболочкой мезопористого кремнезема. Частицы $m \mathrm{SiO}_{2} / \mathrm{Fe}_{3} \mathrm{O}_{4}$ диспергировались в смеси, содержащей структурообразующий агент, деионизованную воду, аммиак и этанол, затем добавлялся тетраэтоксисилан $[11,12]$. Состав смеси и условия синтеза обеспечивали нанесение на частицы оболочек $m \mathrm{SiO}_{2}$ одинаковой толщины. Частицы отделялись центрифугированием, сушились и отжигались при температуре $550^{\circ} \mathrm{C}$. На рис. $1, b$ представлено изображение 
частиц $m \mathrm{SiO}_{2} / \mathrm{Fe}_{3} \mathrm{O}_{4} @ m \mathrm{SiO}_{2}$, полученное с использованием просвечивающего электронного микроскопа (ПЭМ) JEM-2100F, Jeol, Япония. Частицы после покрытия оболочкой сохраняют сферическую форму. Толщина оболочки составила $25 \mathrm{~nm}$. Проведен рентгеноспектральный микроанализ (РСМА) частиц $m \mathrm{SiO}_{2} / \mathrm{Fe}_{3} \mathrm{O}_{4} @ m \mathrm{SiO}_{2}$ с использованием энергодисперсионного рентгеновского спектрометра Oxford Instruments INCA, встроенного в ПЭМ. Карты распределения основных элементов в частицах, представленные на рис. 1, $c$, свидетельствуют о равномерности распределения магнетита в ядре частиц.

Полученные частицы $m \mathrm{SiO}_{2} / \mathrm{Fe}_{3} \mathrm{O}_{4} @ m \mathrm{SiO}_{2}$ со структурой ядро-оболочка обладают химически активной внутренней поверхностью мезопор в оболочке за счет наличия одиночных силанольных групп [15]. Это позволяет проводить функционализацию поверхности пор частиц, а также вводить в поры оболочки лекарственные препараты и использовать такие частицы, например, в качестве контейнеров для токсичных химиопрепаратов. По данным адсорбционного структурного анализа рассчитаны удельная поверхность и объем пор в частицах $m \mathrm{SiO}_{2} / \mathrm{Fe}_{3} \mathrm{O}_{4} @ m \mathrm{SiO}_{2}$, которые составили $250 \mathrm{~m}^{2} / \mathrm{g}$ и $0.15 \mathrm{~cm}^{3} / \mathrm{g}$ соответственно.

Функционализация частиц $\mathrm{mSiO}_{2} / \mathrm{Fe}_{3} \mathrm{O}_{4} @ m \mathrm{SiO}_{2}$ биологически совместимым люминофором - флуоресцеин изотиоцианатом (FITC) [16] - осуществлялась в два этапа. На первом этапе внутренняя поверхность частиц $m \mathrm{SiO}_{2} / \mathrm{Fe}_{3} \mathrm{O}_{4} @ m \mathrm{SiO}_{2}$ функционализировалась $\mathrm{NH}_{2}$-группами аналогично процедуре, описанной в [15]. После этого частицы отжигались при температуре $100^{\circ} \mathrm{C}$ в течение $2 \mathrm{~h}$. На втором этапе проводилась хемосорбция FITC из его спиртового раствора с концентрацией $10 \mathrm{mM}$ в течение двух суток. Затем частицы отделялись центрифугированием и промывались деионизованной водой (с сопротивлением $10 \mathrm{M} \Omega \cdot \mathrm{cm}$ ) для удаления неспецифически связанного FITC. Оставшиеся внутри частиц молекулы FITC химически связаны с поверхностью пор в оболочке.

На рис. 2 приведено распределение гидродинамических диаметров полученных частиц $m \mathrm{SiO}_{2} / \mathrm{Fe}_{3} \mathrm{O}_{4} @ m \mathrm{SiO}_{2} / \mathrm{FITC}$ (схематичное изображение частицы представлено на вставке к рис. 2), измеренное методом динамического светорассеяния (ДСР) на приборе Malvern Zetasizer Nano ZS при температуре $25^{\circ} \mathrm{C}$. Средний гидродинамический диаметр частиц по данным ДСР составляет $285 \pm 25 \mathrm{~nm}$. Таким образом, покрытие частиц $m \mathrm{SiO}_{2} / \mathrm{Fe}_{3} \mathrm{O}_{4}$ оболочкой мезопористого кремнезема и

Письма в ЖТФ, 2017, том 43, вып. 15 


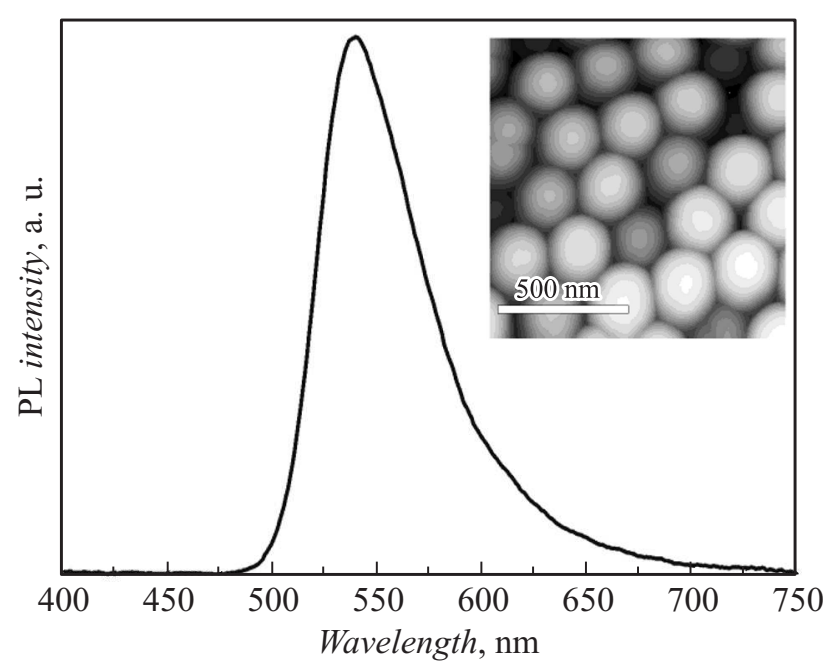

Рис. 3. Спектр фотолюминесценции гибридных частиц $\mathrm{mSiO}_{2} /$ $\mathrm{Fe}_{3} \mathrm{O}_{4} @ m \mathrm{SiO}_{2} / \mathrm{FITC}$. На вставке приведено АCM-изображение частиц.

функционализация внутренней поверхности пористой оболочки люминофором не влияют на монодисперсность частиц (среднеквадратичное отклонение размеров не превышает 10\%).

Спектры фотолюминесценции (ФЛ) частиц $m \mathrm{SiO}_{2} / \mathrm{Fe}_{3} \mathrm{O}_{4} @ m \mathrm{SiO}_{2} /$ FITC измерялись при возбуждении Не-Cd-лазером с длиной волны $325 \mathrm{~nm}$ при комнатной температуре и регистрировались с помощью управляемого компьютером монохроматора МДР-23, оснащенного фотоумножителем ФЭУ-79, работающим в режиме счета фотонов. В спектре ФЛ частиц (рис. 3) наблюдается широкая полоса с максимумом на длине волны $530 \mathrm{~nm}$. На вставке к рис. 3 приведено типичное изображение частиц $m \mathrm{SiO}_{2} / \mathrm{Fe}_{3} \mathrm{O}_{4} @ m \mathrm{SiO}_{2} / \mathrm{FITC}$, нанесенных на $\mathrm{Si}$-подложку, полученное с помощью атомно-силового микроскопа (ACM) NT-MDT SMENA в полуконтактном режиме. Наблюдается упорядоченность в расположении частиц, свидетельствующая об их монодисперсности. По результатам обработки АСМ-изображений 50 частиц путем построения гистограммы распределения размеров с последующей аппроксимацией функцией Гаусса определено, что среднеквадратичное отклонение диаметров частиц не превышает $10 \%$.

Письма в ЖТФ, 2017, том 43, вып. 15 
Люминесцентные свойства частиц $m \mathrm{SiO}_{2} / \mathrm{Fe}_{3} \mathrm{O}_{4} @ m \mathrm{SiO}_{2} / \mathrm{FITC}$ обусловливают возможность отслеживания процесса накопления в опухоли при их использовании, например, в качестве контейнеров для токсичных химиотерапевтических препаратов. Химическое связывание молекул люминофора активной поверхностью пор в оболочке предотвратит его выход из частиц и проникновение в организм.

Таким образом, синтезированы гибридные частицы со структурой ядро-оболочка на основе оксидов железа и кремния. Частицы представляют собой монодисперсные сферические мезопористые частицы кремнезема, заполненные $\mathrm{Fe}_{3} \mathrm{O}_{4}$ и покрытые оболочкой мезопористого кремнезема, внутренняя поверхность которой функционализирована люминофором FITC. Показано, что покрытие частиц, содержащих магнетит, оболочкой мезопористого кремнезема не влияет на форму и монодисперсность частиц. Среднеквадратичное отклонение размеров частиц $m \mathrm{SiO}_{2} / \mathrm{Fe}_{3} \mathrm{O}_{4} @ m \mathrm{SiO}_{2} / \mathrm{FITC}$ не превышает $10 \%$. Показано, что магнетит равномерно распределен внутри ядра. Степень заполнения магнетитом составила 30 vol.\% от объема ядра. В спектре ФЛ частиц наблюдается широкая полоса в видимой области спектра с максимумом на длине волны $530 \mathrm{~nm}$. Полученные гибридные частицы могут найти применение в качестве лекарственного средства для противоопухолевой терапии (как средство для магнитной гипертермии и как контейнер для токсичных химиопрепаратов в системах адресной доставки лекарств). Вместе с тем такие частицы одновременно могут выступать в качестве многофункционального диагностического средства (как контрастное средство при проведении МРТ и как люминесцентный маркер). Вышеперечисленное обусловливает перспективы применения полученных частиц в тераностике онкологических заболеваний.

Авторы благодарят В.В. Соколова за исследование внутренней структуры частиц методом адсорбционного структурного анализа и Е.Ю. Стовпяга за исследование распределения частиц по размерам методом динамического светорассеяния. В.Г. Голубев, Д.А. Курдюков и D.R. Yakovlev благодарят РФФИ (№ 15-52-12011) и DFG в рамках ICRC TRR 160 за финансовую поддержку разработки метода получения нанокластеров магнетита в порах частиц кремнезема. Д.А. Еуров благодарит РФФИ (№ 16-34-01039 мол_а) за финансовую поддержку разработки метода функционализации внутренней поверхности мезопористого кремнезема. Работа выполнена с использованием оборудования федерального ЦКП „Материаловедение и диагностика в передовых технологиях“ (ФТИ им. А.Ф. Иоффе, Санкт-Петербург).

Письма в ЖТФ, 2017, том 43, вып. 15 


\section{Список литературы}

[1] Ghazanfari M.R., Kashefi M., Shams S.F., Jaafari M.R. // Biochem. Res. Int. 2016. V. 2016. P. 7840161.

[2] Wu W., Jiang C.Z., Roy V.A.L. // Nanoscale. 2016. V. 8. P. 19421.

[3] Dutz S., Hergt R. // Nanotechnology. 2014. V. 25. P. 452001.

[4] Moise S., Céspedes E., Soukup D., Byrne J.M., El Haj A.J., Telling N.D. // Sci. Rep. 2017. V. 7. P. 39922.

[5] Lee S.-C., Fu C.-M., Chang F.-H. // Appl. Phys. Lett. 2013. V. 103. P. 163104.

[6] Wu W., He Q.G., Jiang C.Z. // Nanoscale Res. Lett. 2008. V. 3. P. 397.

[7] Deatsch A.E., Evans B.A. // J. Magn. Magn. Mater. 2014. V. 354. P. 163.

[8] Borlido L., Azevedo A.M., Roque A.C.A., Aires-Barros M.R. // Biotechnol. Adv. 2013. V. 31. P. 1374.

[9] Basuki J.S., Jacquemin A., Esser L., Li Y., Boyer C., Davis T.P. // Polym. Chem. 2014. V. 5. P. 2611

[10] Riaz S., Bashir M., Naseem S. // IEEE Trans. Magn. 2014. V. 50. P. 4003304.

[11] Trofimova E.Yu., Kurdyukov D.A., Yakovlev S.A., Kirilenko D.A., Kukushkina Yu.A., Nashchekin A.V., Sitnikova A.A., Yagovkina M.A., Golubev V.G. // Nanotechnology. 2013. V. 24. P. 155601.

[12] Eurov D.A., Kurdyukov D.A., Kirilenko D.A., Kukushkina J.A., Nashchekin A.V., Smirnov A.N., Golubev V.G. // J. Nanopart. Res. 2015. V. 17. P. 82.

[13] Стовпяга Е.Ю., Еуров Д.А., Курдюков Д.А., Смирнов А.Н., Яговкина М.А., Григорьев B.Ю., Романов B.B., Yakovlev D.R., Голубев В.Г. // ФТТ. 2017. T. 59. B. 8. C. 1598.

[14] Li L., Jiang W., Luo K., Song H., Lan F., Wu Y., Gu Z. // Theranostics. 2013. V. 3. P. 595

[15] Еуров Д.А., Грудинкин С.А., Курдюков Д.А., Медведев А.В., Стовпяга Е.Ю., Голубев В.Г. // Письма в ЖТФ. 2015. Т. 41. В. 19. С. 1.

[16] Hercules D.M., Frankel H. // Science. 1960. V. 131. P. 1611. 